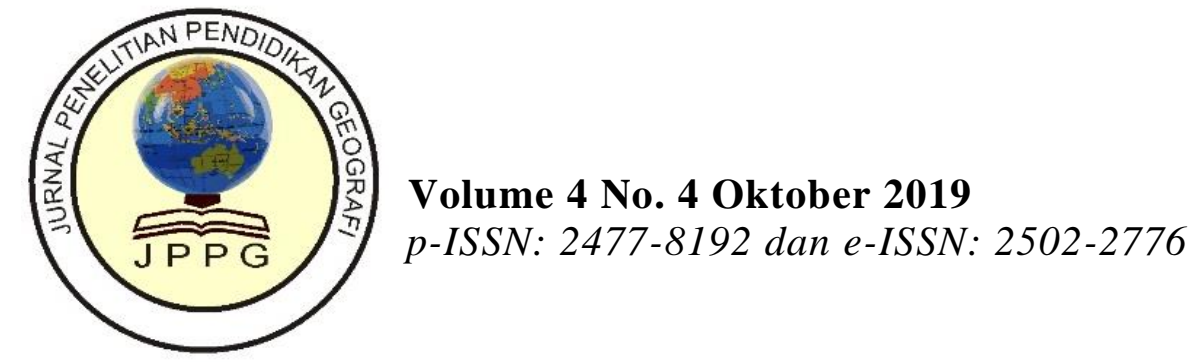

\title{
DESKRIPSI TINGKAT PRODUKSI JAGUNG DI DESA LAKALAMBA, KABUPATEN SAWERIGADI, KABUPATEN BARAT DESKRIPSI TINGKAT PRODUKSI JAGUNG DI DESA LAKALAMBA, KABUPATEN SAWERIGADI, KABUPATEN BARAT
}

\author{
Wa Ode Sitti Hartina Ilham Pamoro ${ }^{1}$, Ramli ${ }^{2}$ \\ ${ }^{1}$ Program Studi Pendidikan Geografi \\ Universitas Halu Oleo \\ Email: hartinailham015@gmail.com \\ ${ }^{2}$ Program Studi Pendidikan Geografi \\ Universitas Halu Oleo \\ Email: ramlilombe@gmail.com
}

(Received: 3 September 2019; Accepted: 29 Oktober 2019; Published: 31 Oktober 2019)

C2019 - Jurnal Penelitian Pendidikan Geografi. Ini adalah artikel dengan

akses terbuka dibawah licenci CC BY-NC-4.0 (http://creativecommons.org/licenses/by-nc/4.0).

\begin{abstract}
Lakalamba Village has a maize plantation area of \pm 200 ha and \pm 350 ha of paddy fields that are not functioning due to several obstacles faced by the community. This study aims to increase corn crop production, and find out the obstacles faced by farmers in an effort to increase corn production. However, the method used in this study is descriptive qualitative. Data collection techniques used were observation, interviews, and documentation. Data was obtained from 35 informants in Lakalamba Village. In determining the description of increased corn crop production in Lakalamba Village, Sawerigadi Subdistrict, West Muna Regency, it must be done by good farming methods such as using modern farming tools for managing agricultural land both during cultivation, planting and even at harvest. . Paying attention to the conditions for land irrigation during the dry season such as making reservoirs. Eradication of pests, diseases and weeds must be sprayed to reduce the possibility of attacks from pests and diseases. The use of high quality seeds must be used to obtain good corn production. The use of fertilizers must be considered and how to provide fertilizer must be measured and given at the right time, in the afternoon and in the morning
\end{abstract}

Keywords: Production of Corn Plants, Lakalamba, West Muna.

\section{ABSTRAK}

Desa Lakalamba memiliki lahan perkebunan jagung seluas $\pm 200 \mathrm{Ha}$ dan \pm 350 Ha lahan persawahan yang tidak difungsikan karena beberapa kendala yang dihadapi oleh masyarakat. Penelitian ini bertujuan untuk peningkatkan produksi tanaman jagung, dan mengetahui kendala yang dihadapi petani dalam upaya peningkatan produksi tanaman jagung. Adapaun metode yang digunakan dalam penelitian ini adalah kualitatif deskriptif. Teknik pengumpulan data yang digunakan adalah observasi, wawancara, dan dokumentasi. Data diperoleh dari 35 informan di Desa Lakalamba Dalam menentukan gambaran peningkatan produksi tanaman jagung di Desa Lakalamba Kecamatan Sawerigadi Kabupaten Muna Barat harus dilakukan dengan cara bertani yang baik seperti menggunakan alat pertanian moderen untuk pengelolahan lahan pertanian baik pada saat pengelolahan, penanamna dan bahkan pada saat panen. Memperhatikan kondisi untuk pengairan lahan pada saat musim kemarau seperti pembuatan waduk. Pemberantasan hama, penyakit dan tanman gulma harus dilakukan penyemprotan untuk menekan kemungkinan terjadinya serangan dari hama maupun penyakit. Penggunaan bibit unggul yang berkualitas harus digunakan untuk mendapatkan produksi 
tanman jagung yang baik. Penggunaan pupuk harus diperhatikan dan cara memberikan pupuk harus ditakar dan diberikan pada waktu yang tepat yaitu pada sore hari dan pagi hari.

Kata kunci : Produksi Tanaman Jagung, Lakalamba, Muna Barat.

\section{PENDAHULUAN}

Pertanian adalah kegiatan pemanfaatan sumber daya hayati yang dilakukan manusia untuk menghasilkan bahan pangan, bahan baku industri, atau sumber energi, serta untuk mengelola lingkungan hidupnya. Pertanian dalam pengertian yang luas mencakup semua kegiatan yang melibatkan pemanfaatan makhluk hidup (termasuk tanaman, hewan, dan mikroba) untuk kepentingan manusia. Sedangakan dalam arti sempit, pertanian juga diartikan sebagai kegiatan pemanfaatan sebidang lahan untuk membudidayakan jenis tanaman tertentu, terutama yang bersifat semusim. Tanaman jagung sudah lama diusahakan petani Indonesia dan merupakan tanaman pokok setelah padi. Penduduk kawasan timur Indonesia seperti Nusa Tenggara Timur, Madura, sebagian maluku, dan Irian Jaya sudah biasa menggunakan jagung sebagai makanan pokok sehari-hari. Produksi jagung Indonesia sebagian besar berasal dari pulau Jawa $( \pm 66 \%)$ dan sisanya berasal darp propinsi luar Jawa terutama Lampung, Sulawesi Utara, Sulawesi Selatan, Sumatra Utara, dan Nusa Tenggara Timur.

Jagung memiliki peranan penting dalam industri berbasis agribisnis. Jagung dimanfaatkan untuk konsumsi, bahan baku industri pangan, industri pakan ternak dan bahan bakar. Kebutuhan jagung dari tahun ke tahun terus mengalami peningkatan seiring berkembangnya industri pakan dan pangan. Kendala dalam budidaya jagung yang menyebabkan rendahnya produktivitas jagung antara lain adalah serangan hama dan penyakit. Hama yang sering dijumpai menyerang tanaman jagung adalah ulat penggerek batang jagung, kutu daun, ulat daun, ulat penggerek tongkol, ulat grayak, lalat bibit, ulat tanah. Sedangkan Bulai, Karat, penyakit gosong, penyakit busuk tongkol adalah penyakit yang sering muncul di tanaman jagung dan dapat menurunkan produksi jagung.Upaya pengendalian oleh petani pada saat ini adalah dengan menggunakan pestisida atau bahan kimia lainnya yang tidak ramah lingkungan. Pengendalian Hama Terpadu (PHT) yang mengintegrasi komponen pengendalian yang selaras terbukti tidak hanya meningkatkan produksi jagung tetapi juga pendapatan petani. Sistim PHT melibatkan semua komponen yang berpeluang untuk menekan atau mencegah hama untuk mencapai ambang batas populasi merusak secara ekonomi (economic injury level/economic threshold) (Wilson, 1990)

Kabupaten Muna Barat adalah sebuah Kabupaten yang ada di Propvinsi Sulawesi Tenggara yang juga memiliki lahan pertanian yang cukup luas. Desa Lakalamba merupakan desa yang ada di kecamatan Sawerigadi Kabupaten Muna Barat yang berada di antara Desa Marobea dan Desa Wandoke yang jumlah penduduknya mencapai $\pm 160 \mathrm{kk}$, yang secara geografis terletak di sebelah Barat Kabupaten Muna Barat. Secara umum desa lakalamba sudah tergolong daerah berkembang, hal ini ditandai dengan sarana dan prasarana pendidikan serta pelayanan kesehatan yang sudah memadai bagi masyarakat setempat. (BPS. Muna Barat 2016)

Berdasarkan observasi awal diperoleh data tentang Desa Lakalamba memiliki lahan perkebunan jagung seluas $\pm 200 \mathrm{Ha}$ dan \pm 350 Ha lahan persawahan yang tidak difungsikan karena beberapa kendala yang dihadapi oleh masyarakat sehingga dalam pengelolaan lahan persawahan. seperti kurangnya air untuk keperluah irigasi, SDM, sarana dan prasarana., pendidikan dan pengetahuan serta sarana dan prasarana yang kurang memadai sehingga masyarakat kesulitan dalam mengelola lahan tersebut dan sebagian besar masyarakat lebih memilih mengelolah tanaman jagung.

\section{METODE PENELITIAN \\ Waktu dan Lokasi Penelitian}

Penelitian ini telah dilaksanakan di Desa Lakalamba Kecamatan Sawerigadi Kabupaten Muna Barat pada bulan Agustus 2018.

\section{Jenis Penelitian}

Jenis penelitian ini adalah penelitian kualitatif deskriptif, yaitu menjelaskan secara rinci mengenai tingkat kesuburan lahan pertanian terhadap produksi tanaman jagung di Desa Lakalamba Kecamatan sawerigadi Kabupaten Muna Barat. 
Informan Penelitian

Informan dalam penelitian ini adalah:

1. Informan kunci meliputi, kepala desa Lakalamaba.

2. Informan Utama berjumlah 30 orang meliputi, Masyarakat Desa Lakalamba yang berprovesi sebagai petani.

3. Informan tambahan meliputi, Masyarakat Desa Lakalamba

Teknik Pengumpulan Data

Dalam usaha untuk pengumpulan data dalam penelitian ini, penulis menggunakan cara sebagai berikut:

1. Observasi

2. Wawancara

3. Dokumentasi

Teknik Pengolahan Data

Tehnik analisis data kualitatif menurut Miles dan Huberman seperti yang dikutip oleh Salim 2006), menyebutkan ada tiga langkah pengelolahan data kualitatif, yakni:

1. Reduksi Data (Data Reduction)

2. Penyajian Data (Data Display)

3. Penarikan Kesimpulan

(Conclusion

Drawing and Verification).

\section{HASIL PENELITIAN}

\section{Deskripsi produksi tanaman jagung Desa Lakalamba Kecamatan Sawerigadi Kabupaten Muna Barat}

Dalam upaya pengelolahan lahan, masyarakat memiliki pemahaman dan pengetahuan yang baik sehingga untuk meningkatkan produksi tanaman jagung bisa terus berkembang, hal inilah yang membuat masyarakat yang ada didesa Lakalamba bisa keluar dari hidup yang sulit, dari upaya kepala desa yang memberikan contoh menananm tanaman jagung kuning untuk dijual dan memberikan hasil yang memuaskan, sehingga masyarakat beralih untuk berkebuntanaman jagung kuning, dan lambat laun sampai terbentuk kelompok usaha tani sehingga bisa saling membantu sesama petani jagung kuning baik dari kalangan petani kecil dan petani besar, dan inisiatif dari kepala desa yang mengadakan alat pertanian moderen yang sangat membantu meningkatkan produksi tanaman jagung kuning ini sehingga produksi tanaman jagung kuning lebih produktif dan masih sangat mungkin untuk berkembang.
Tanggapan dan pemahaman masyarakat petani jagung mengenai waktu tanam, pola tanam, dan cara tanam menunjukan bahwa pemahaman masyarkat desa Lakalamba sudah berkembang dari pengelolahan secara primitif menjadi petani moderen, sudah menggunakan alat pertanian moderen untuk mengelolah lahan, menananm pun sudah menggunakan alat pertanian dan pemberian pupuk diberikan secara otomatis sudah tidak manual, jadi para petani hanya tinggal mengontrol pertumbuhan jagung kuning sehingga produksi tanaman jagung kuning lebih produktif, dan petani sangat paham betul bahwa penanaman sangat dipengaruhi oleh kondisi cuaca.

Dalam pemilihan dan penggunaan bibit sudah pasti menggunakan bibit yang berkulitas, masyarakat sangat setuju dengan penggunaan bibit unggul yang baik akan menghasilkan produksi tanaman jagung yang baik pula. Mereka menyadari bahwa pemilihan bibit unggul yang baik merupakan salah satu faktor untuk meningkatkan produksi tanaman jagung yang berkualitas.

Dalam upaya pemupukan dalam pemberian pupuk untuk tanaman jagung cukup baik yaitu dengan menggunakan pupuk organaik dari pada menggunakan pupuk yang dibuat oleh pabrik dengan anggapan pupuk organik lebih menghemat biaya pengeluaran, selain itu pupuk-pupuk yang dijual ditoko-toko banyak mengandung zat kimia yang dapat merusak kesuburan lahan dan bahkan dapat merusak tanaman jagung apabila dilakukan secara berlebihan berbeda dengan pupuk organik dan pupuk buatan yang dibikin sendiri oleh para petani yang menggunakan kotoran hewan.

Dalam upaya untuk waktu dan cara pemberian pupuk masyarakat Desa Lakalamba tidak setuju dengan cara pemberian pupuk dengan sembarangan dan kapan saja bisa diberikan, masyarakat Desa Lakalamba sangat memahami pemberian pupuk dengan jumlah takaran yang pas akan sangat bermanfaat bagi tanaman jagung dari pada memeberikan pupuk secara asal-asalan, dan pemberian pupuk tidak diberikan kapan saja tetapi memiliki pola waktu untuk memberikan pupuk, waktu yang tepat untuk pemberian pupuk pada tanaman jagung yaitu pada saat pagi hari atau pukul 7 pagi dan sore hari atau sekitar pukul 5 sore.

Untuk pengairan tanaman jagung masyarakat Desa Lakalamba setuju, masyarakat memahami bahwa dengan mengatur perairan pada musim kemarau untuk tanaman jagung 
maka tanaman jagung tidak akan kekeringan dan akan tumbuh dengan subur dan baik pula sehingga tidak mengganggu hasil panen yng diinginkan jadi untuk yang mengalami kekurangan air pada saat musim kemarau akan sangat baik untu membuat waduk dan untuk lahan pertanian yang berada disekitar aliran sungai harus sering memperhatikan jumlah debit air pada saat menanam di musim kemarau.

Pengendalian hama dan penyakit untuk tanaman jagung tidak setuju dengan pemberantasan penyakit pada tanaman jagung dimulai pada saaat jagung berumur tuju hari karena pada saat umur tuju hari tanman jagung bulum tampak baru tunas kecil yang munccul sehingga para petani tidak setuju, waktu yang bagus untuk memulai pemberantasan hama dan penyakit pada tanaman jagung yaitu dimulai pada saat jagung berumur 14 hari.

Pengendalian gulma tanaman jagung cukup baik para petani sangat memahami tentang pengendalian gulma pada saat tanaman jagung mulai tumbuh karena pada saat seperti inilah tanaman gulma akan sangat mengganggu dan meresakan tanaman jagung maka dari itu penyemprotan tanaman gulma harus dilakukan untuk menekan pertumbuhan tanaman gulma dan harus disemprotkan secara rutin.

\section{Kendala yang dihadapi petani jagung dalam meningkatkan kesuburan laha terhadap produksi tanaman jagung}

Selain mendiskripsikan tingkat produksi tanaman jagung, berikut ini peneliti juga mendiskripsikan kendala yang dihadapi petani jagung dalam meningkatkan produksi tanaman jagung, untuk mendiskripsikan diajukan beberapa pertanyaan sebagai berikut:

1. Sarana dan prasarana

2. Serangan hama

3. Kurangnya pengetahuan tentatang sistempertanian modern

Sehingga dapat dideskripsikan Kendala yang dihadap petani jagung dalam pengelolahan lahan untuk meningkatkan produksi tanaman jagung pada umumnya ada beberapa faktor yaitu kurangnya sarana dan prasarana yang memadai merupakan hambatan yang serius bagi masyarakat Desa Lakalamba dalam bertani, sehingga dalam usaha untuk meningkatkan kesuburan lahan untuk meningkatkan produksi tanman jagung pasti tidak seperti yang diharapkan oleh para petani, seperti kendala untuk mngelolah lahan yang terlambat karena menunggu giliran, menyewa orang lagi untuk mengoprasikan alat tersebut dan lain sebagainya.

Selain sara dan prasarana yang menjadi kendala dalam meningkatkan kesuburan lahan terhadap produksi tanaman jagung selanjutnya yaitu serangan hama, serangan hama yang sangat dikhawtirkan yaitu hama tikus dan babi yang memakan tanman jagung, bahkan dapat menyebapkan gagal panen, maka dari itu hama tersebut harus dimusnakan dengan cara menyemprot tanman jagung secara rutin dan menggunakan cara lain seperti memasan perangkap dan lain sebagainya.

\section{KESIMPULAN}

Berdasarkan hasil penelitian tentang meningkatkan kesuburan lahan terhadap produksi tanaman jagung dapat disimpulkan: 1) Upaya meningkatkan kesuburan lahan untuk meningkatkan produksi tanaman jagung harus dilakukan dengan cara bertani yang baik seperti menggunakan alat pertanian moderen untuk pengelolahan lahann pertanian baik pada saat pengelolahan, penanamna dan bahkan pada saat panen. Memperhatikan kondisi untuk pengairan lahan pada saat musim kemarau seperti pembutan waduk. Pemberantasan hama, penyakit dan tanman gulma harus dilakukan penyemprotan untuk menekan kemungkinan terjadinya serangan dari hama maupun penyakit. Penggunaan bibit unggul yang berkualitas harus digunakan untuk mendapatkan produksi tanman jagung yang baik. Penggunaan pupuk harus diperhatikan dan cara memberikan pupuk harus ditakar dan diberikan pada waktu yang tepat yaitu pada sore hari dan pagi hari; 2) Faktor yang menjadi kendala yang dihadapi petani jagung dalam meningkatkan kesuburan lahan terhadap produksi tanman jagung di Desa Lakalamba Kecamatan Sawerigadi Kabupaten Muna Barat yaitu sarana dan prasarana yang kurang memadai sehingga dalam pengelolahan lahan untuk meningkatkan kesuburan lahan juga pasti akan mengalami masalah. Pembasmian hama dan penyakit harus dibasmi pada saat tanaman jagung mulai tumbuh dan dilakukan penyemprotan dengan rutin agar tidak merusak tanaman jagung.

\section{SARAN}

Saran dalam penelitian ini sebagai berikut: 1) Kepada pemerintah Desa Lakalamba diharapkan lebih memperhatikan lagi dan terus ikut membantu dalam usaha petai untuk meningkatkan produksi 
tanaman jagung karena sangat perlu bantuan dari pemerintan; 2) Jika ingin berhasil dalam pengelolahan lahan, meningkatkan kesuburan dan ingin meningkatkan produksi tanaman jagung, harus memperhatikan apa yang menjadi kendala dalam pengelolahan lahan meingkatkan kesuburan untuk menigkatkan produksi tanaman jagung; 3) Kepada peneliti selanjutnya jika dalam risetnya memiliki obyek yang sama dengan penelitian ini agar meneliti lebih mendalam dan manfaatnya dapat memberikan peranan baik bagi para petani.

\section{UCAPAN TERIMA KASIH}

Terima kasih kepada kedua orang tua, Bapak Drs. Ramli, M.Si, selaku pembimbing I serta para reviewer dan editor Jurnal Penelitian Pendidikan Geografi.

\section{DAFTAR PUSTAKA}

Ade, Rukmana. (2006). Pengelolahan Kelas dan Berbagai Faktor Yang Mempengaruhi. Jakarta: Remaja Rosdakarya.

Agus, Salim. (2006). Teori dan Paradigma Penelitian Sosial. Yogyakarta: Tiarawacana

Anonim. (2007). Pengelolahan Laboratorium Fisika Sekolah Menengah Atas. Jakarta: Direktorat Jendral Mananjemen Pendidikan Dasar dan Menengah; Direktorat Pembinaan Sekolah Menengah Atas

Assauri, Sofyan. (1980). Manajemen Produksi dan Operasi. Jakarta. LBFE UI.

Keraf, G. (1995). Eksposisi. Jakarta: Gramedia.

Purwono, dan R. Hartono. (2006). Bertanam Jagung Unggul.. Penebar Surabaya. Jakarta.

Sutopo, H. B. (2002). Metodologi Penelitian Kualitatif: Teori dan Aplikasinya Dalam Penelitian. Surakarta: Sebelas Maret University Press

Tarigan, Henry Guntur. (1994). Membaca Sebagai Suatau Keterampilan Berbahasa. Bandung: Penerbit. Angkasa.

Wilson, E. (1990). Postmodernism and Society. London-UK: Macmillan 